\title{
Amniotic Fluid Stem Cells
}

\author{
Gianni Carraro, Orquidea H. Garcia, \\ Laura Perin, Roger De Filippo and David Warburton \\ Saban Research Institute, Children's Hospital Los Angeles \\ USA
}

\section{Introduction}

The amniotic fluid or liquor amnii, was first isolated and studied during the beginning of the $20^{\text {th }}$ century (Brace et al., 1989). More recently, in the 1960s and 1970s there was an increased interest in characterization and culture of the cells contained in the amniotic fluid (Huisjes HJ, 1970; Marchant GS, 1971). Nevertheless, most all of these studies were directed at using amniotic fluid, and the cells contained within, for determining the health of the fetus during development, or to provide a general characterization of the amniotic fluid. Although the discovery of stem cells, in particular bone marrow stem cells, occurred in the 1960 's, it was not until recently that the possibility of isolating stem cells from the amniotic fluid was investigated. Amniotic fluid stem cell isolation and characterization is therefore fairly recent, dating back to the early 1990's (Torricelli et al., 1993).

The study of amniotic fluid-derived stem cells (AFDSCs) has captured the attention of researchers and clinicians for several reasons. First, AFDSCs can be collected during amniocentesis and isolated from material that would be otherwise discarded. Therefore, their use is not subject to the ethical debate that surrounds the use of embryonic stem cells. Second, like other fetal derived stem cells, storage of AFDSCs is easy and achieved at minimal costs. AFDSC populations can be easily expanded, and have shown the capability of being stored over long periods of time with no adverse effects (Da Sacco et al., 2010). Furthermore, the "banking" of AFDSCs from developing fetuses, may guarantee a source of stem cells with a matching immune profile to that of the recipient. Most importantly, the extensive characterization of a specific subset of AFDSCs positive for the marker c-Kit ${ }^{+}$(De Coppi et al., 2007), have displayed no tumor formation following transplant into an animal model, even after several months. These cells, known simply as amniotic fluid stem cells (AFSC) have been at the forefront of AFDSC research and will be discussed in depth later. Finally, as a source of stem cells collected before birth AFDSCs may become an invaluable source of stem cells for direct treatment of various genetic disorders treatable in utero (Turner CG et al., 2009).

The potential applications and implications of AFDSCs in regenerative medicine and therapeutic treatments are significant, however; AFDSCs research is still in its infancy and much work is required to properly characterize AFDSCs and determine their effectiveness. In this chapter, we describe the different AFDSCs that have been isolated to date, list their characteristics, and provide an overview of the different organs in which AFDSCs have been used in vitro or in vivo to develop this stem cell population into a viable therapeutic strategy. 


\section{The amniotic cavity}

The amniotic fluid is contained in the amniotic cavity that, in humans, starts forming as early as seven days post fertilization, and is delimited by a membrane called amnion. The formation of the amniotic cavity is a result of the cavitation of the epiblast. The amnion is formed by the cells of the epiblast, by the side facing the cytotrophoblast. This is the first appearance of the amniotic ectoderm, and at this stage it is still a continuum of the portion of the epiblast that will form the embryo. The amnion formation is completed at fourteen days post fertilization and is constituted of two layers: the amniotic ectoderm (inner layer facing the amniotic fluid) and the amniotic mesoderm (outer layer). The amnion has the important function of protecting the embryo and controlling the composition and the volume of the amniotic fluid. In humans, after seventeen weeks of gestation the amnion becomes surrounded and fused with another membrane, the chorion, and is therefore incorporated into the placenta. At the beginning of the formation of the amniotic cavity, active transport of solutes from the amnion, followed by passive movement of water, comprise the amniotic fluid.

In mice the amniotic cavity starts forming at embryonic stage E0.5 as a result of apoptotic events in the epiblast. At this stage, there is still the presence of a proamniotic cavity and the amnion that will start forming during gastrulation, is not yet defined. At approximately day E7.5 the amniotic cavity is formed and one day later the embryo starts the rotation process. At the end of the rotation, the embryo will be surrounded by the amnion. Surrounding the amnion are two more membranes, the visceral yolk sac and most externally the parietal yolk sac (Kaufman MH, 1992). These membranes represent three distinct layers surrounding the mouse embryo. Differently from human, in mice, the amnion does not fuse with the chorion and is not included in the placenta.
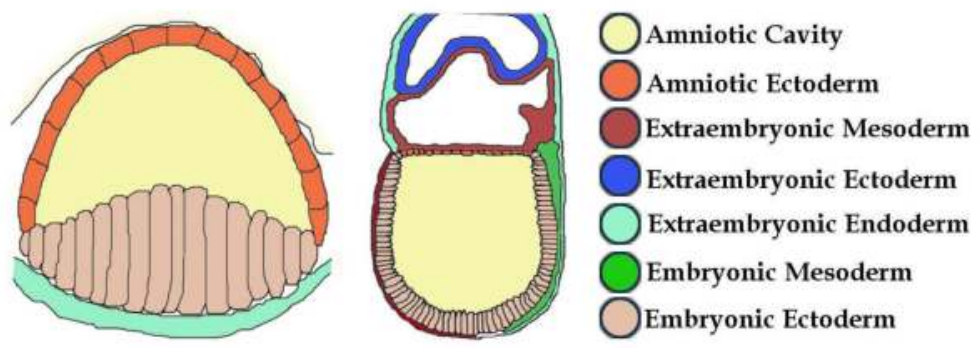

Fig. 1. Amniotic cavity formation

Twelve days post fertilization the human amniotic cavity is delimitated by the amnion (that at this stage is composed by the amniotic ectoderm) and the embryonic ectoderm (left). In the 7.5-day mouse embryo (right) the amnion is formed by the amniotic mesoderm and the amniotic ectoderm.

In mammals the embryo is immersed in the amniotic fluid contained inside the amniotic cavity. In human (left) the cavity is delimited by the amniotic ectoderm and the amniotic mesoderm that constitute the amnion, and by the chorion. The amniotic ectoderm is in direct contact with the amniotic fluid. In mouse (right) the amnion is surrounded by two extra membranes, the visceral and parietal yolk sac. 

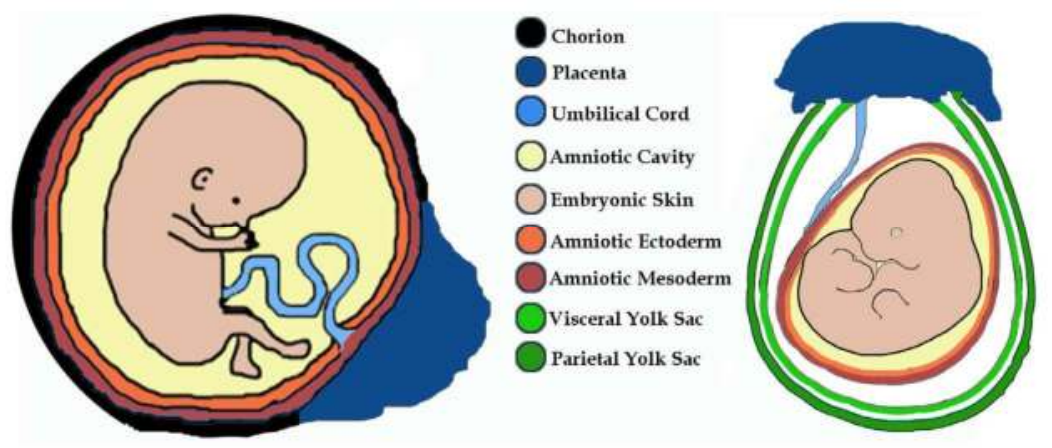

Fig. 2. Extra-embryonic membranes

\section{The amniotic fluid}

The amniotic fluid is the liquid present in the amniotic cavity and is constituted of about $98 \%$ water. This volume and composition change continuously during the different gestational stages. The volume of the amniotic fluid at the beginning of the pregnancy is multiple times the volume of the fetus, but at the end of gestation, at forty weeks, it will represent only a quarter of the volume of the fetus. Early during development, when the fetus has not yet started urination and deglutition, the plasma from the mother is surmised to play an important role in the composition of the amniotic fluid, and even though the mechanism is not completely understood, active transport of solutes is probably present between the amnion into the amniotic cavity, therefore creating a gradient for water recruitment (Bacchi Modena A and Fieni S, 2004). The exchange of fluid through the skin that occurs until keratinization is also an important contributor to the osmolarity of the amniotic fluid. After keratinization, urination, swallowing and secretion due to breathing events also contributes to the composition of the amniotic fluid. Urine start to be part of the composition of the amniotic fluid at about eight weeks and its amount will increase during gestation, reaching a flow rate of up to $900 \mathrm{ml}$ /day at the end of gestation (Lotgering FK et al., 1986). Similarly, at approximately eight weeks, the fetus begins swallowing and secreting material including lung fluid and urine. Secretion of lung fluid is due to an active transport of chloride through the epithelium of the lung (Adamson TM et al., 1973). Sampling of amniotic fluid at later stages of the pregnancy is used to monitor lung development via the presence or absence of surfactant lipids and proteins secreted into the amniotic fluid.

The cells present in the amniotic fluid have both embryonic and extraembryonic origins. Approximately forty years ago, researchers attempted to characterize these cells by cytological and biochemical parameters (Morris HHB et al., 1974). Early characterization distinguished four epithelial cell types in the amniotic fluid: large eosinophilic cells, large cyanophilic cells, small round cyanophilic cells, and polygonal eosinophilic cells (Huisjes HJ, 1970). Today we know that most of the cells of the amniotic fluid are derived from the skin, digestive, urinary (Fig. 3) and pulmonary tracts of the fetus and from the surrounding amnion. We also know that the proportion and type of cells changes continuously during the different gestational stages. Some cells may also be derived from the mother, passing through the placenta into the fluid itself. The size of the cells contained in the fluid can 
range from 6um to 50um and the shape can vary notably from round to squamous in morphology (Siddiqui and Atala, 2004).

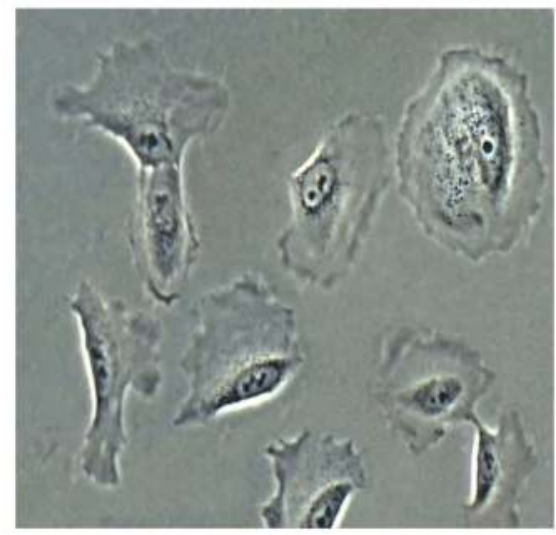

Fig. 3. Kidney amniotic fluid cells

Amniotic fluid contains cell populations derived from several different tissues. Pictured above is a population of cells isolated using kidney specific markers (40X magnification).

\section{Amniotic fluid-derived stem cells}

AFDSCs belong to the group of stem cells present in extra embryonic tissues; all sharing the feature of belonging to material that is discarded after birth or that can be collected during amniocentesis. Besides the amniotic fluid, the amnion, umbilical cord and placenta have shown to contain stem cells that can be isolated at birth (Bailo $\mathrm{M}$ et al., 2004; Banas RA et al, 2008; Brunstein CG et al., 2006; Fukuchi Y et al., 2004).

The first studies of AFDSCs, were completed using mesenchymal amniocytes isolated from sheep. These cells showed the ability to expand in vitro and to integrate into a scaffold (Kaviani A et al., 2001). In the following years, the identification of cells expressing the marker Oct4 (Prusa et al., 2003), or co-expressing Oct4, CD44 and CD105 (Tsai et al., 2004) were discovered in amniotic fluid. More recently a clonal population of AFDSCs derived from human and mouse were isolated and characterized (De Coppi P et al., 2007). These cells named AFSCs, were isolated through positive selection for the marker CD117 (or c-Kit), and represented $1 \%$ of cells derived from amniocentesis. AFSCs express the marker of "stemness", Oct4, and the embryonic stem cell (ESC) marker SSEA-4. Furthermore AFSCs express markers characteristic of mesenchymal and neural stem cells such as CD29, CD44, CD73, CD90, and CD105. Interestingly, these cells are negative for markers of hematopoietic stem cells such as CD34 and CD133.

Recently, a screen for the expression profile of cells present in the amniotic fluid was reported (Da Sacco S et al., 2010). This screening analyzed cells obtained from human amniotic fluid between gestational weeks 15 to 20 and showed that markers such as Oct4 and CD117 are stably expressed during gestation. Furthermore, while markers for ectoderm are stably expressed during gestation, markers for the early endoderm and mesoderm are more abundant during early gestation and tend to disappear after 17 to 18 weeks. During 
the same time, organ specific markers start to become highly expressed. A full proteome analysis (Tsangaris G et al., 2005) using bi-dimensional gel electrophoresis and mass spectrometry, has allowed the identification of specific proteins expressed in the cells present in the amniotic fluid. This analysis has confirmed that amniotic fluid contains a heterogeneous population of cells, both differentiated and with characteristics of stem cells. In the following paragraphs a detailed description of the approaches used to differentiate AFDSCs into various lineages is presented.

When considering the use of amniotic fluid stem cells for regenerative medicine and various therapeutic interventions, clinicians and researchers agree that the ease of amniotic fluid stem cell isolation and culture make them attractive candidates for further research and development. As mentioned previously, amniotic fluid stem cells are isolated from samples of amniotic fluid collected during routine amniocentesis. This routine procedure (Fig. 4.) occurs during weeks 16-20 of a pregnancy, where approximately 10-20 milliliters of amniotic fluid is collected and split into two samples (Trounson, 2007). One sample serves as the test sample to screen for genetic and gestational abnormalities, while the other sample serves as a back up. When the back-up sample is no longer needed, some diagnostic laboratories donate this "medical waste" to research laboratories for stem cell isolation and further research. Throughout this entire process, neither the mother, nor the fetus is harmed, making the collection of these cells ethically neutral.

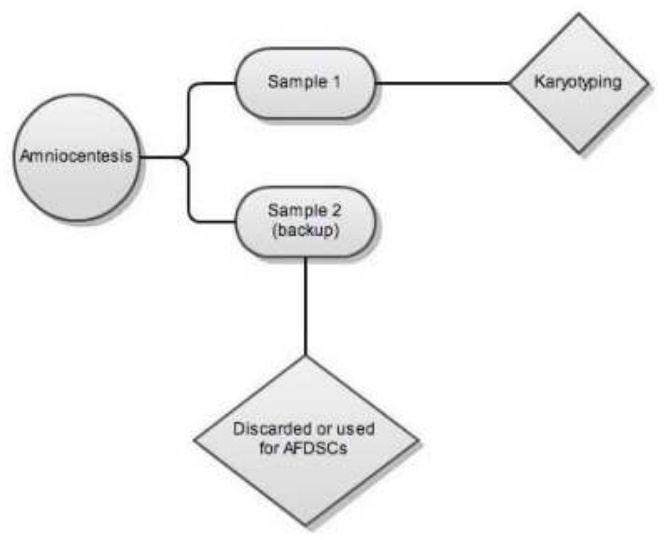

Fig. 4. Diagram for Amniotic Fluid-Derived Stem Cells isolation

The use of AFDSCs for the treatment of congenital anomalies has great potential, but in most cases is still far from clinical applications. Nerveless there is at least one case in which cells derived from amniotic fluid have been successfully used for tissue engineering. Mesenchymal cells isolated from amniotic fluid have been expanded in vitro using a chondrogenic medium and than seeded into a biodegradable scaffold and maintained in a rotating bioreactor (Kunisaki SM et al., 2006). The cells used in this report were not specifically analyzed for pluripotency or selected for specific markers, and were considered progenitor cells by the authors. Being a mixed population of cells they likely contained both committed lineages and AFDSCs, but most importantly they were able to differentiate into cartilage in vitro into a three-dimensional scaffold and maintain these characteristics for as long as fifteen weeks. 


\section{Amniotic fluid stem cells}

Within amniotic fluid are a menagerie of cells previously described as AFDSCs, however approximately $1 \%$ of the cells contained within the fluid have been identified and designated as amniotic fluid stem cells (AFSC). AFSCs represent the most characterized clonal population of pluripotent stem cells isolated from amniotic fluid. AFSCs can be isolated by immunoselection with magnetic microsphere or FACS for the receptor for stem cell factor (c-Kit or CD117). The clonal origin of these cells was tested by integration of a single provirus (CMMP-eGFP) and analysis of subclones. Analysis of the subclones grown at limiting dilution maintained the signature integration at the same position (a 4 kilobase BamH1 fragment). The sublones were able to differentiate into lineages representative of the three embryonic germ layers. After isolation AFSCs will grow slowly for about one week (this phenomenon differs in AFSCs isolated at different gestational stages), and will then start to proliferate faster following this initial 'lag-phase' (Siddiqui MM and Atala A, 2004). AFSCs grow in absence of feeder layer when plated on Petri dishes and have a doubling time of about 36 hours (De Coppi et al, 2007). The isolated population can then be cultured quite readily on plastic or glass. If maintained at a sub-confluent state, AFSCs do not differentiate. Clones should be cultured in medium containing $\alpha$-minimal essential medium supplemented with $20 \%$ Chang-B and $2 \%$ Chang-C solutions, $20 \%$ fetal bovine serum (FBS), $1 \%$ L-glutamine, and 1\% antibiotics. Clones should be periodically monitored for the presence of a correct karyotype, and for the expression of specific markers such as Oct4, SSEA4, CD29, CD44, and the absence of markers such as CD45, CD34, and CD133 (see De Coppi et al., 2007 for a complete list of specific markers). AFSCs are pluripotent and can be differentiate in vitro into several lineages (De Coppi et al., 2007; Siddiqui MM and Atala A, 2004). Numerous groups have reported the high renewal capacity of these cells without differentiation or loss of telomere length (Da Sacco et al., 2010).
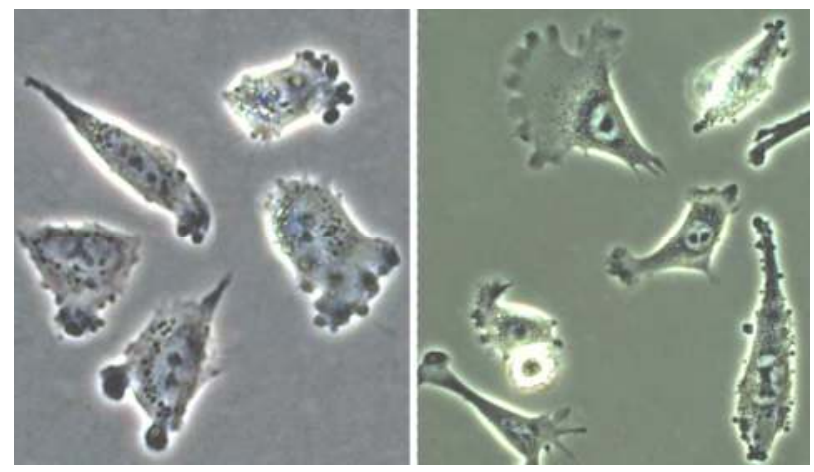

Fig. 5. Amniotic Fluid Stem Cells

Human amniotic fluid stem cells (left) and mouse amniotic fluid stem cells (right) that were isolated via selection for the surface marker CD117. Both cells have similar phenotypes (40X magnification).

\subsection{Differentiation of amniotic fluid stem cells}

C-kit positive amniotic fluid stem cells are pluripotent and have been successfully differentiated into all three germ layer cell types: endoderm, ectoderm and mesoderm. 
From these pluripotent cells, various phenotypes have been derived in vitro. Osteogenic, endotheilial, hepatic, neurogenic, adipogenic and myogenic progenitor cell lines are a few of the lineages derived to date. Derivation of these lines has been verified by morphogenesis, phenotypic analysis and a litany of biochemical assays for characteristic of each cell type. Culture and manipulation of these cells into various progenitors has become so streamlined, that various standard protocols have been established (Delo et al., 2006). Although a significant milestone, differentiation of AFSC into various lineages in vitro is quite distinct from the in vivo potential, use and efficacy of these cells. Transplantation of these cells into a living system, or the use of these cells to create a functional organ hinge on the ability of these cells not simply to survive in vivo, however; success is dependant on the physiological functionality of these cells to perform within the anatomy. The future of regenerative medicine and cellular therapy hinges on this principle, and not surprisingly, AFSC have also shown remarkable capabilities in vivo in numerous organs.

\subsubsection{Hematopoietic system}

AFSC expressing CD117+ and Lin-, derived from both human and mouse, have been shown to have hematopoietic potential (Ditadi A et al., 2010). These cells were capable of differentiating into erythroid, myeloid, and lymphoid lineages in vitro as well as in vivo, in the peripheral blood of irradiated mice. Furthermore, single cells analysis was able to assess the expression of several genes important during different stages of hematopoietic differentiation.

\subsubsection{Brain}

A fully mature neural differentiation remains to be tested for cells derived from amniotic fluid. Neural differentiation was fist reported during the initial identification of AFSCs (De Coppi et al., 2007). Subsequently, a study for the differentiation of AFSCs into dopamine neurons (Donaldson AE et al., 2009), showed that AFSCs express specific markers of neural progenitors and immature dopamine neurons, but were unable to fully differentiate in vitro or in vivo. Analyzing other cell lines isolated from amniotic fluid (McLaughlin D et al., 2006) it was shown that phenotypic characteristics of dopaminergic neurons are present, while markers for other neurons, like cholinergic, GABAergic, and adrenergic were absent or had a weak expression.

\subsubsection{Bone}

AFSC cultured with an osteogenic medium, can secrete alkaline phosphatase and produce mineralized calcium, characteristic of functional osteoblasts. Furthermore, when implanted into an immunodeficient mouse, AFSC where able to produce mineralized tissue in vivo (De Coppi et al., 2007). A comparison between AFDSCs and bone morrow-derived stem cells (MSCs), has shown that while MSCs undergo a faster differentiation, AFDSCs can maintain and increase the mineralization for a longer period (Peister A et al., 2011).

\subsubsection{Kidney}

AFSC therapy in the kidney is progressing quickly and is arguably at the forefront of AFSC research. Research groups using AFSC in kidney have not only been able to demonstrate the ability of AFSC to populate the kidney and form renal structures, but also to protect the kidney during injury and aid in the regeneration of renal tissue. The groundbreaking 
studies, which follow, paved the way for much of the other organ specific experimentation, in particular, that of the lung.

In the embryonic kidney, AFSC have been shown to differentiate into tubular and glomerular structures and express characteristic kidney cell markers and genes (Perin et al., 2007). In this study, metanephric kidneys were isolated from embryonic mice, microinjected with approximately $1000 \mathrm{CM}$-dil labeled c-kit positive AFSC and placed on a membrane for cultivation in an incubator. What is remarkable is that even though the embryonic kidney was not fully formed at the beginning of the experiment, labeled AFSC were seen to integrate into developing $C$ and S-shaped structures at day 5, and at day 6, integrated into tubular and glomerular structures. Reverse transcriptase-PCR for human kidney specific genes, not previously expressed by the AFSC, identified expression of ZO-1, claudin and glial-derived neurotrophic factor were detected. This experiment showed the ability of AFSC to survive within developing tissue, engraft into that tissue, differentiate into the appropriate cell type and aid in the population of an organ.

Furthermore, it has recently been discovered that AFSC injected into the acutely injured kidney stimulate the release of anti-inflammatory cytokines and attenuate pro-inflammatory signaling greatly reducing apoptosis and allowing for proliferation and repopulation of injured epithelia (Perin L. et al., 2011). In this study, nude mice, deprived of water for a period of 22 hours, were given an intramuscular injection of a 50\% hypertonic glycerol solution in water. This type of injury induces rhabdomyolysis-related acute tubular necrosis (ATN) ultimately resulting in renal dysfunction. Following intrarenal injection of $1.2 \times 10^{6}$ cells, AFSC were observed, via luciferase, to persist at the site of injury most notably at 48 and 72 hours, with persistence in the kidneys for up to 6 days. Additionally, analysis of the cytokine milieu showed the markedly different expression patterns of cytokines at 14 days post transplant. Mice with ATN only, and no AFSC transplant, showed a general trend of increased pro-inflammatory cytokines and decreased anti-inflammatory cytokine expression. On the other hand, mice with ATN and intra-renal injection of AFSC demonstrated that the anti inflammatory cytokines increased over the 14 day study period, while pro-inflammatory cytokines decreased. In another study after glycerol-induced acute kidney injury (Hauser PV et al., 2010) a comparison between mesenchymal stem cells (MSCs) and AFSCs has shown that while MSCs where mainly inducing proliferation, AFSCs had an antiapoptotic effect. Thus, these data suggests that AFSCs responds in a paracrine manner in response to injury and/or stress, and modulation of immune signaling is what contributes to the alleviation of symptoms associated with the injury.

\subsubsection{Lung}

In utero, the developing lungs of the fetus are filled with fetal lung liquid which is actively secreted into the amniotic fluid. In the late gestational period, surfactant produced by the fetal lungs contributes to the composition of amniotic fluid and can be measured to determine the developmental stage of the surfactant system within the fetal lungs. Thus, it makes sense that when looking for regenerative therapies for lung tissue, AFSC are a logical source.

In our preliminary transplantation studies, it was found that c-kit positive AFSC can incorporate into mouse embryonic lung and express human lung epithelial cell markers (Carraro, et al., 2008). In the same study, following naphthalene injury in nude mice, and intravenous transplantation of $1 \times 10^{6}$ AFSC, cells were observed to preferentially remain at the site of injury when compared to uninjured controls when visualized via luciferase assay. 
Additionally, following oxygen injury in the lung it was observed that AFSC appear to exhibit alveolar epithelial type II phenotypes, widely surmised to be a lung epithelial stem cell, suggesting that once in the lung these cells are stimulated to differentiate in response to injury. Furthermore, in vivo, the efficiency of AFSC diapedesis, integration and expression in upper and lower airway epithelia is increased following injury. After oxygen injury, AFSC were observed to be taken into the SP-C positive alveolar epithelial lineage, whereas after naphthalene injury AFSC are taken up into the CC10-positive Clara cell lineage. AFSC presence persisted in the lung after injury, but decreased over time. Although integration into the adult lung following injury is a relatively rare event, additional therapeutic mechanisms displayed by these cells, such as the modulation of the inflammatory milieu and their differentiation into type II lineages demonstrate great potential in the stimulation of lung repair mechanisms.

Lung researchers have also begun investigating the potential of seeding AFSC on a scaffold to regenerate tissue for transplantation. Due to the overwhelming shortage of donor lungs, and the inability of modern medicine to effectively treat or halt many progressive lung diseases such as idiopathic pulmonary fibrosis, research focus has shifted to the bioengineering of functional lung tissue. Decellularization of lungs, where all cells are removed from the extracellular matrix of an organ, has become an investigational target. In 2010 a whole lung decellularization method and tissue engineering study using neonatal lung epithelia was reported (Peterson et al., 2010). What is remarkable about this study is that while it has long been known that epithelial cells seeded on a decellularized lung matrix were capable of forming alveolar epithelia, this study demonstrated the functionality of the regenerated tissue. The decellularized, repopulated and regenerated lungs were transplanted into a rat and were able to support short-term perfusion and gas exchange. In another study, researchers were able to seed not only epithelium, but also endothelium as well on a decellularized rat lung. Following transplantation, blood gas analysis of the engineered lung demonstrated that the lung was capable of gas exchange (Ott et al., 2010). Thus decellularized lung matrix seems currently to be the most promising scaffold for whole lung regeneration and the possibility of using an autologous source of stem cells such as AFSC to repopulate the scaffold could have great potential in the future.

\subsubsection{Heart}

The use of AFSC as a regenerative therapy for cardiac disease and congenital disorders has shown the efficacy of transplanted cells providing both cardio protective potential, as well as the engineering of various cardiac components such as valves and tissue (Bollini et al., 2011; Schmidt et al., 2007; \& Hilkfer et al., 2011).

The engineering of heart valves, obtained from normal human amniotic fluid samples, sorted via positive selection for the CD133 molecule, was elegantly demonstrated in 2007 (Schmidt et al., 2007). Both CD 133 positive and negative cell populations were cultured in media that caused differentiation towards endothelial phenotypes. CD133+ cell populations showed the ability to produce functional endothelial cells indicated by the expression of eNOS and CD141, while CD133- cells displayed a more mesenchymal phenotype. CD133- cells were then seeded on biodegradable PGA leaflets that were positioned within a mold to form a valve structure. After 14 days, CD133+ cells were seeded onto the scaffold as well. While regeneration of both extracellular matrix and endothelial layers were generated, functional testing revealed that the heart valves were sufficiently functional only under low-pressure conditions. This failure to perform at 
physiological levels was not due to the scaffold material, which displayed linear properties prior to being seeded with cells, but instead was a result of the incomplete formation of collagen suggesting that the method of seeding and culture upon the biodegradable scaffolding needs to be optimized further to be able to transplant these engineered valves into patients. In an acute myocardial infarction model, ischemia, produced via ligation of the left anterior descending coronary artery, was followed with intravenous transplantation of AFSC and reperfusion of the heart for 2 hours. Animals treated with $5 \times 10^{6}$ cells intravenously, showed a significant decrease in infarct size and number of apoptotic cardiomyocityes when compared to control animals administered saline alone (Bollini et al., 2011). Staining to determine the localization and viability of transplanted AFSC showed that two hours post transplant, cells localized to the lung, spleen and heart. AFSC within the heart co-stained for epithelia vWf and $\alpha$-SMA, suggestive of the potential of these cells to commit to endothelium and smooth muscle following transplant. Long term retention and engraftment in the injured myocardial tissue did not occur however. The secretion of thymosin beta 4 in vitro, a cardio protective factor, suggests that the transplantation of AFSC in this model exert a paracrine effect.

\subsection{Why use AFSC in regenerative medicine?}

When selecting a stem cell population for use in a regenerative or therapeutic capacity, there are a myriad of factors that need to be considered. The pluripotentiality, the ability of the cells to differentiate into different germ layers and tissue types, is of fundamental importance if one is isolating cells to treat diseases or developmental deficiencies in which progenitor cells within the patient are compromised or overwhelmed. Additionally, the plasticity of the cells and their ability to differentiate to repopulate different populations within an organ, and repopulate them correctly is crucial. Furthermore, the behavior of the cells after injection must be carefully studied and characterized. Tumorogenicity, immunogenicity and the propensity to form teratomas and further exacerbate a disease state can rule out various cellular therapies simply due to risk. To date, amniotic fluid stem cells have demonstrated the ability to meet all of these criteria and behave remarkably well in a regenerative and therapeutic capacity. Amazingly pluripotent, less immunogenic, and not prone to teratoma formation, AFSCs have quickly risen near the top of the list of stem cell therapies to continue developing.

Furthermore, recently induced pluripotent stem (iPS) cells have been prepared from cells derived from amniotic fluid (AF-iPS), and have shown high efficiency of transformation and colony formation after just six days (Li C et al., 2009). Although not fully understood, this is probably due to the presence of an epigenetic status closer to the embryonic state (Galende $\mathrm{E}$ et al., 2010). Reprogramming of somatic cells using the four specific factors, Oct4, Sox2, Klf4, and c-Myc has the potential to provide pluripotent stem cells specific for patients, thus AFiPS seem to be more easily reprogrammed to pluripotency compared to adult cells or cells from neonates.

\section{Conclusion}

The studies outlined in this chapter demonstrating the capability that AFSC have shown in vitro and in vivo show that AFSC are viable targets for regenerative medicine and for future therapeutic treatment strategies. Although the relatively early stage of AFSC research limits 
a full understanding of the behaviors, properties and characteristics of these fascinating cells, research to date demonstrates two important mechanisms of action that need to be investigated further.

First, AFSC have the potential to serve as an in vivo treatment to stimulate endogenous cell populations, repopulate injured tissue or ameliorate inflammatory or disease states. These properties are advantageous when dealing with disease or injury states in which there is enough functional tissue remaining in an organ to drive repopulation. The only caveat to endogenous cellular stimulation is that the remaining tissue (that is being stimulated) must be functional, meaning that it is free of genetic disorders or mutations. If remaining tissue within an organ meets these standards, exogenous AFSC transplantation can be used to stimulate endogenous progenitors to repopulate, protect progenitor or other cell types from further injury, or AFSC may be driven to differentiate to repopulate this tissue, as was indicated in the aforementioned embryonic studies.

Second, AFSC have the potential to engineer whole organs in vitro to be transplanted into a recipient. This strategy is advantageous in situations where, for whatever reason, enough functional tissue does not remain to repopulate with a cell transplant. Whole organ reengineering, perhaps the holy grail of regenerative medicine, involves a symphony of factors, events and coordinated expression patterns to form intricate niche structures including endothelium, epithelium, extracellular matrix and so on. The engineering of a whole organ will in fact require a much deeper understanding of these cells as signaling cascades and response elements need to be coordinated to engineer every cell type within a specific organ. However the recent findings of Kajtsura et al (2011) support the our notiion that the genome within a single stem cell type may prove to be sufficiently plastic to simultaneously derive all of the cell lineages required for complex organ repair or engineering.

\section{References}

Adamson TM, Brodecky V, Lambert TF. The production and composition of lung liquid in the in-utero foetal lamb. In Comline RS, Cross KW, Dawes GS (eds): Foetal and Neonatal Physiology. Cambridge University Press, 1973.

Bacchi Modena A., Fieni S. Amniotic fluid dynamics. Acta Bio Medica Ateneo Parmense. 75: 11-13. 2004.

Bailo M., Soncini M., Vertua E., Signorini P.B., Sanzone S., Lombardi G., Arienti D., Calamani F., Zatti D., Paul P. et al. Engraftment potential of human amnion and chorion cells derived from term placenta. Transplantation 78: 1439-1448. 2004.

Banas, RA, Trumpower C., Bentlwjewsky C., Marshall V., Sing G. and Zeevi A. Immunogenicity and immunomodulatory effects of amnion-derived multipotent progenitor cells. Hum Immunol 69: 321-328. 2008

Bollini S., Cheung K.K., Riegler J., Dong X., Smart N., et al. Amniotic Fluid Stem Cells Are Cardioprotective Following Acute Myocardial Infarction. Stem Cells and Development. May 2011.

Brace RA, Wolf EJ. Normal amniotic fluid volume changes throughout pregnancy. Am J Obstet Gynecol. 1989 Aug; 161:382-8.

Brunstein CG, Wagner JE. Cord blood transplantation for adults. Vox Sang. 91(3):195-205. 2006 
Carraro G, Perin L, Sedrakyan S, Giuliani S, Tiozzo C, Lee J, Turcatel G, De Langhe SP, Driscoll B, Bellusci S, Minoo P, Atala A, De Filippo RE, Warburton D. Human amniotic fluid stem cells can integrate and differentiate into epithelial lung lineages. Stem Cells 2008; 26: 2902-2911.

De Coppi P., Bartsch Jr. G., Siddiqui M.M., Xu T., Santos C.C., et al. Isolation of amniotic stem cell lines with potential for therapy. Nture Biotechnology 25 (1): 100-106( 2007).

Da Sacco S., De Filippo R.E., \& Perin L. Amniotic fluid as a source of pluripotent and multipotent stem cells for organ regeneration. Curr Opin Organ Transplant. 2010.

Delo DM., De Coppi P, Bartsch Jr G., \& Atala A. Amniotic Fluid and Placental Stem Cells. Methods in Enzymology 419: 426-436. 2006.

Ditadi A, de Coppi P, Picone O, Gautreau L, Smati R, Six E, Bonhomme D, Ezine S, Frydman R, Cavazzana-Calvo M, Andrea-Schmutz I. Human and murine amniotic fluid cKit+Lin- cells display hematopoietic activity. Blood. 113(17):3953-60. 2009.

Donaldson AE, Cai J, Yang M, Iacovitti L. Human amniotic fluid stem cells do not differentiate into dopamine neurons in vitro or after transplantation in vivo. Stem Cells Dev. 18(7):1003-12. 2009.

Fukuchi Y, Nakajima H, Sugiyama D, Hirose I, Kitamura T, Tsuji K. Human placentaderived cells have mesenchymal stem/progenitor cell potential. Stem Cells. 22(5):649-58. 2004.

Galende E, Karakikes I, Edelmann L, Desnick RJ, Kerenyi T, Khoueiry G, Lafferty J, McGinn JT, Brodman M, Fuster V, Hajjar RJ, Polgar K. Amniotic fluid cells are more efficiently reprogrammed to pluripotency than adult cells. Cell Reprogram. 12:2. 117-125. 2010.

Hauser PV, De Fazio R, Bruno S, Sdei S, C Grange C, Bussolati B, Benedetto C, Camussi G. Stem Cells Derived from Human Amniotic Fluid Contribute to Acute Kidney Injury Recovery. The American Journal of Pathology. 177:4. 2011-2021. 2010.

Hilkfer A., Kasper C., Hass R., \& Haverich A. Mesenchymal stem cells and proenitor cells in connective tissue engineering and regenerative medicine : is there a future for transplantation? Langenbeck's Archives of Surgery, 396: 4, 489-497. 2011.

Huisjes HJ. Origin of the cells in the liquor amnii. Americ. J. Obstet. Gynec. 106: 1222-1228. 1970.

Kajstura J, Rota M, Hall SR, Hosoda T, D'Amario D, Sanada F, Zheng H, Ogórek B, RondonClavo C, Ferreira-Martins J, Matsuda A, Arranto C, Goichberg P, Giordano G, Haley KJ, Bardelli S, Rayatzadeh H, Liu X, Quaini F, Liao R, Leri A, Perrella MA, Loscalzo J, Anversa P. Evidence for human lung stem cells. N Engl J Med. 2011 12;364(19):1795-806.

Kaufman, MH. The Atlas of Mouse Development. Academic Press, CA. 1992.

Kaviani A, Perry TE, Dzakovic A, Jennings RW, Ziegler MM, Fauza DO. The amniotic fluid as a source of cells for fetal tissue engineering. J Pediatr Surg. 36(11):1662-5. 2001.

Kunisaki SM, Jennings RW, Fauza DO. Fetal cartilage engineering from amniotic mesenchymal progenitor cells. Stem Cells Dev. 15(2):245-53. 2006. 
Li C, Zhou J, Shi G, Ma Y, Yang Y, Gu J, Yu H, Jin S, Wei Z, Chen F, Jin Y. Pluripotency can be rapidly and efficiently induced in human amniotic fluid-derived cells. Hum Mol Genet. 18(22):4340-9. 2009.

Lotgering FK, Wallenburg HCS. Mechanisms of production and clearance of amniotic fluid. Semin Perinatol ;10: 94. 1986.

Marchant GS. Evaluation of Methods of Amniotic Fluid Cell Culture. American Journal of Medical Technology. 37: 391-396. 1971.

McLaughlin D, Tsirimonaki E, Vallianatos G, Sakellaridis N, Chatzistamatiou T, Stavropoulos-Gioka C, Tsezou A, Messinis I, Mangoura D. Stable expression of a neuronal dopaminergic progenitor phenotype in cell lines derived from human amniotic fluid cells. J Neurosci Res. 83(7):1190-200. 2006.

Morris HHB and Bennett MJ. The classification and origin of amniotic fluid cells. Acta Cytologica. 18: 2. 149-154. 1974.

Ott HC, Clippinger B, Conrad C, Schuetz C, Pomerantseva I, Ikonomou L, Kotton D, Vacanti JP. Regeneration and orthotopic transplantation of a bioartificial lung. Nature Medicine: Vol. 16, No. 8. 2010.

Peister A, Woodruff MA, Prince JJ, Gray DP, Hutmacher DW, Guldberg RE. Cell sourcing for bone tissue engineering: Amniotic fluid stem cells have a delayed, robust differentiation compared to mesenchymal stem cells. Stem Cell Res. 2011.

Peterson T.H., Calle E.A., Zhao L., Lee E.J., Gui L., et al. Tissue-Engineered Lungs for in Vivo Implantation. Science, 2010.

Perin L, Sedrakyan S, Giuliani S, Da Sacco S, Carraro G, Shiri L, Lemley KV, Rosol M, Wu S, Atala A, Warburton D, De Filippo R. Protectice Effect of Human Amniotic Fluid Stem Cells in an Immunodeficient Mouse Model of Acute Tubular Necrosis. PLoS ONE 5(2): e9357.

Perin L, Giuliani S, Jin D, Sedrakyan S, Carraro G, Habibian R, Warburton D, Atala A, De Filippo RE. Renal differentiation of amniotic fluid stem cells. Cell Prolif . 40:9. 2007.

Prusa AR, Marton E, Rosner M, Bernaschek G, Hengstschl $\sqrt{ }$ §ger M. Oct-4-expressing cells in human amniotic fluid: a new source for stem cell research? Hum Reprod. Jul;18(7):1489-93. 2003.

Schmidit D., Achermann J., Odermatt B., Breymann C., Mol A., et al. Prenatally Fabricated Autologous Human Living Heart Valves Based on Amniotic Fluid-Derived Progenitor Cells as Single Cell Source. Circulation, 116: 164-170. 2007.

Siddiqui MM and Atala A. Amniotic fluid-derived pluripotent cells. Handbook of stem cells. 2:16. 175-179. 2004.

Torricelli F, Brizzi L, Bernabei PA, Gheri G, Di Lollo S, Nutini L, Lisi E, Di Tommaso M, Cariati E. Identification of hematopoietic progenitor cells in human amniotic fluid before the 12th week of gestation. Ital J Anat Embryol. Apr-Jun;98(2):119-26. 1993.

Trounson, A. A fluid means of stem cell generation. Nature Biotechnology 25 (1): 62-63 (2007).

Tsai MS, Lee JL, Chang YJ, Hwang SM. Isolation of human multipotent mesenchymal stem cells from second-trimester amniotic fluid using a novel two-stage culture protocol. Hum Reprod. 19(6):1450-6. 2004. 
Tsangaris G, Weitzdrfer R, Pollak D, Lubec G, Fountoulakis M. The amniotic fluid cell proteome. Electrophoresis. 26(6):1168-73. 2005.

Turner CG, Fauza DO. Fetal tissue engineering. Clin Perinatol. 36(2):473-88. 2009. 


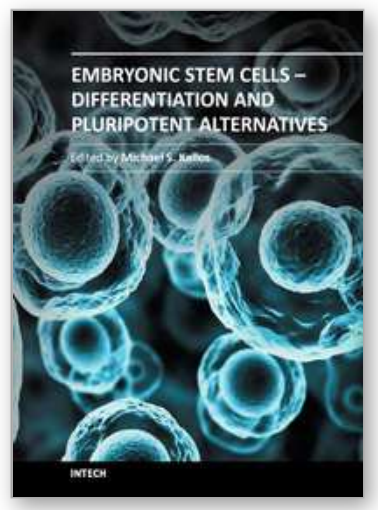

\author{
Embryonic Stem Cells - Differentiation and Pluripotent Alternatives \\ Edited by Prof. Michael S. Kallos
}

ISBN 978-953-307-632-4

Hard cover, 506 pages

Publisher InTech

Published online 12, October, 2011

Published in print edition October, 2011

The ultimate clinical implementation of embryonic stem cells will require methods and protocols to turn these unspecialized cells into the fully functioning cell types found in a wide variety of tissues and organs. In order to achieve this, it is necessary to clearly understand the signals and cues that direct embryonic stem cell differentiation. This book provides a snapshot of current research on the differentiation of embryonic stem cells to a wide variety of cell types, including neural, cardiac, endothelial, osteogenic, and hepatic cells. In addition, induced pluripotent stem cells and other pluripotent stem cell sources are described. The book will serve as a valuable resource for engineers, scientists, and clinicians as well as students in a wide range of disciplines.

\title{
How to reference
}

In order to correctly reference this scholarly work, feel free to copy and paste the following:

Gianni Carraro, Orquidea H. Garcia, Laura Perin, Roger De Filippo and David Warburton (2011). Amniotic Fluid Stem Cells, Embryonic Stem Cells - Differentiation and Pluripotent Alternatives, Prof. Michael S. Kallos (Ed.), ISBN: 978-953-307-632-4, InTech, Available from: http://www.intechopen.com/books/embryonic-stemcells-differentiation-and-pluripotent-alternatives/amniotic-fluid-stem-cells

\section{INTECH}

open science | open minds

\section{InTech Europe}

University Campus STeP Ri Slavka Krautzeka 83/A 51000 Rijeka, Croatia Phone: +385 (51) 770447 Fax: +385 (51) 686166 www.intechopen.com

\section{InTech China}

Unit 405, Office Block, Hotel Equatorial Shanghai No.65, Yan An Road (West), Shanghai, 200040, China 中国上海市延安西路65号上海国际贵都大饭店办公楼405单元 Phone: +86-21-62489820

Fax: +86-21-62489821 
(C) 2011 The Author(s). Licensee IntechOpen. This is an open access article distributed under the terms of the Creative Commons Attribution 3.0 License, which permits unrestricted use, distribution, and reproduction in any medium, provided the original work is properly cited. 